\title{
Electrocatalytic Oxidation Removal of Phenol from Aqueous Solution with Metal Oxides Doped Carbon Aerogel
}

\author{
Gui-Fen Lv, Yuan-Hua Chen, Tao Yang and Jian-Guo Li* \\ Soil Fertilizer and Resources Environment Institute, Jiangxi Academy of Agricultural Sciences, \\ 330200 Nanchang, China
}

\begin{abstract}
Metal oxides (manganese oxide, $\mathrm{MnO}$, manganese dioxide, $\mathrm{MnO}_{2}$, copper oxide, $\mathrm{CuO}$, zinc oxide, $\mathrm{ZnO}$ and nickel oxide, $\mathrm{NiO}$ ) doped carbon aerogel (CA) were prepared and used as catalysts in heterogeneous oxidation of phenol from aqueous solution in a three-dimensional (3D) electrode reactor. Textural characterization of metal oxides doped CA showed that the metal oxide nanoparticles are dispersed separately throughout the carbon matrix. The experimental results showed that phenol was degraded mainly by hydroxyl $(\bullet \mathrm{OH})$ radicals. The presence of metal oxides accelerated $\bullet \mathrm{OH}$ radical generation. The $\bullet \mathrm{OH}$ radical quantity depends on the type of metal oxide. The n-type semiconductor was more active than p-type semiconductor for $\bullet \mathrm{OH}$ radical generation. Furthermore, acceleration effect of $\bullet \mathrm{OH}$ radical generation catalyzed by metal oxides doped $\mathrm{CA}$ was investigated and demonstrated.
\end{abstract}

Keywords: phenol, electrocatalytic oxidation, metal oxides doped carbon aerogel

\section{Introduction}

Wastewater containing phenolic compounds cannot be degraded completely through conventional processes because of their poor biodegradability. Electrochemical process is one of the advanced oxidation processes, and it has been proved to be an effective process for removal of organic compounds from wastewater. ${ }^{1}$ In essence, electrochemical processes involve the heterogeneous electron transfer between a solid electrode and the ionic species in an electrolytic solution, and the rate of electrochemical reaction is dependent on electron transfer rate, and can be based on the transformation of oxygen into hydroxyl $(\bullet \mathrm{OH})$ radicals which attack most organic compounds. ${ }^{2}$ However, because of their low selectivity a large fraction of $\bullet \mathrm{OH}$ radicals will be lost to water matrix. A further development is resulted from the addition of transition metal oxides to the system to enhance the transformation of oxygen into $\bullet \mathrm{OH}$ radicals.

Transition metal oxides have proved to be active in catalytic reactions of complete degradation of phenolic compounds in wastewaters. For example, Ji et al. ${ }^{3}$ and Induja and Raghavan ${ }^{4}$ found that copper oxide is an effective catalyst for removal of phenol in aqueous solution. Christoskova et al..$^{5}$ synthesized nickel oxide $(\mathrm{NiO})$ for

*e-mail: 1ijg1972@163.com purifying wastewater containing phenol. The activity and selectivity of transition metal oxides catalysts depend on the oxidation state of metal ions and their coordination in the lattice, the surface cation oxygen bond strength, the content of active oxygen, and so on. ${ }^{6}$

Compared with the traditional two-dimensional (2D) electrochemical electrode reactor, the three-dimensional (3D) electrochemical electrode reactor has the third electrode, ${ }^{7}$ or particle electrode or bed electrode which basically consists of granular or fragmental materials which are filled between two counter electrodes. At an appropriate voltage in direct current electric field, these particles will be induced and polarized to form a large number of charged microelectrodes in which its one side can be considered as anode while the other side is charged the opposite. 3D electrode reactor has advantages such as high surfaceto-volume ratio, short distance between electrodes, good transferring effect and low energy consumption which makes it popular in application of wastewater treatment, especially in removal of phenolic compounds. ${ }^{8}$

In this study, a 3D electrode reactor was used. According to our previous experiments, ${ }^{9,10}$ carbon aerogel (CA) has proved to be a kind of promising material as particle electrodes used in phenol oxidation. However, literature survey revealed that no further work has been reported on the synthesis of metal oxides doped CA and its electrocatalytic oxidation mechanism for phenol 
degradation in a 3D electrode reactor. Based on this, in this study CA particles were used as particle electrodes and catalyst supports, while manganese oxide $(\mathrm{MnO})$, manganese dioxide $\left(\mathrm{MnO}_{2}\right)$, copper oxide $(\mathrm{CuO})$, zinc oxide $(\mathrm{ZnO})$ and nickel oxide $(\mathrm{NiO})$ were used as catalyst candidates. The goals of this investigation were to investigate the relationship between the phenol removal by metal oxides doped CA and the kind of metal oxides as well as to quantity $\bullet \mathrm{OH}$ radicals generation.

\section{Experimental}

\section{Chemicals}

Phenol, metal ( $\mathrm{Mn}, \mathrm{Cu}, \mathrm{Zn})$ nitrates, $\mathrm{KMnO}_{4}$ and $\mathrm{Mn}\left(\mathrm{CH}_{3} \mathrm{COO}\right)_{2}$ were obtained from Guangzhou Chemical Reagent Factory (China). All solutions were prepared with deionized water.

\section{Procedures}

MnO-doped CA and CuO-doped CA were prepared by impregnating aerogel particles with the corresponding metal nitrates, the aerogel particles were previously ground and sieved in the 5-10 mesh range before impregnation. The resulting samples were heated to $900^{\circ} \mathrm{C}$ with a heating rate of $5{ }^{\circ} \mathrm{C} \mathrm{min}^{-1}$ and kept at this carbonization temperature for $3 \mathrm{~h}$ under nitrogen flow $\left(800 \mathrm{~mL} \mathrm{~min}^{-1}\right)$.

$\mathrm{ZnO}$-doped CA was prepared by impregnating $\mathrm{CA}$ particles with zinc nitrate aqueous solutions, the CA particles were previously ground and sieved in the 5-10 mesh range before impregnation. The resulting sample was heated to $600{ }^{\circ} \mathrm{C}$ with a heating rate of $5{ }^{\circ} \mathrm{C} \mathrm{min}^{-1}$ and kept at this carbonization temperature for $3 \mathrm{~h}$ in $\mathrm{N}_{2}$ flow $\left(800 \mathrm{~mL} \mathrm{~min}^{-1}\right)$.

$\mathrm{MnO}_{2}$-doped CA was prepared by liquid phase coprecipitation technique. The starting materials for the preparation of $\mathrm{MnO}_{2}$ are $\mathrm{KMnO}_{4}$ and $\mathrm{Mn}\left(\mathrm{CH}_{3} \mathrm{COO}\right)_{2} \cdot 4 \mathrm{H}_{2} \mathrm{O}$. Firstly, the $\mathrm{KMnO}_{4}$ was dissolved in deionized water to form $0.1 \mathrm{M}$ solution. To the solution of $\mathrm{KMnO}_{4}$, CA particles were dispersed and stirred for $12 \mathrm{~h}$. After complete homogenization of the mixture, $0.15 \mathrm{M}$ $\mathrm{Mn}\left(\mathrm{CH}_{3} \mathrm{COO}\right)_{2} \cdot 4 \mathrm{H}_{2} \mathrm{O}$ were added dropwise under constant stirring. The well mixed precipitate of $\mathrm{MnO}_{2}$-doped CA was filtered and dried at $100{ }^{\circ} \mathrm{C}$ for $12 \mathrm{~h}$.

Similarly, NiO-doped CA was prepared by $\mathrm{Ni}\left(\mathrm{NO}_{3}\right)_{2}$ and $\mathrm{NaOH}$. The $\mathrm{Ni}\left(\mathrm{NO}_{3}\right)_{2}$ was dissolved in deionized water to form $0.1 \mathrm{M}$ solution, then CA particles were added into the solution and stirred for $12 \mathrm{~h}$. After complete homogenization of the mixture, $0.2 \mathrm{M} \mathrm{NaOH}$ were added dropwise under constant stirring. The well mixed precipitate of NiO-doped CA was filtered and dried at $100^{\circ} \mathrm{C}$ for $12 \mathrm{~h}$.

\section{Samples characterization}

The structures of the samples were studied by transmission electron microscope (TEM, JEM-2010HR, Japan) and X-ray diffraction (XRD, D-MAX 2200 VPC, Japan). UV-Vis spectra of phenol, relative quantity and concentration of hydroxyl $(\bullet \mathrm{OH})$ radicals were measured by UV-Vis-NIR (near infrared) spectrophotometer (UV-3150, Japan).

Experimental device set up and electrochemical process

The 3D electrode reactor used is shown in Figure 1, the main anode and cathode were made from graphite and stainless steel plates $10 \mathrm{~cm}$ apart from each other, $20 \mathrm{~g}$ metal oxides doped CA particles were packed between the two main electrodes. The volume of the 3D electrodes was $10 \mathrm{~cm} \times 10 \mathrm{~cm} \times 2 \mathrm{~cm}$. Air was purged into the $3 \mathrm{D}$ electrode reactor by a micropore plate from the bottom of the reactor. What needs to be explained is that the function of air is not only to agitate mixed wastewater and improve the mass transfer rate but also to supply reactants required for the electrode reaction. When electric potential in direct current electric field is applied across the CA particles, every particle is polarized and behaves as an anode on one side and a cathode on the other side. Thus reactions take place on both sides of the electrode particle. A total of $50 \mathrm{~mL}$ simulated wastewater was fed into the $3 \mathrm{D}$ electrode reactor prior to each run. The reactor was timed starting when the direct current (DC) power and compressed air supply were switched on. After each run, this $50 \mathrm{~mL}$ treated wastewater was drained completely, another $50 \mathrm{~mL}$ simulated wastewater was again fed into the $3 \mathrm{D}$ electrode reactor for the next run.

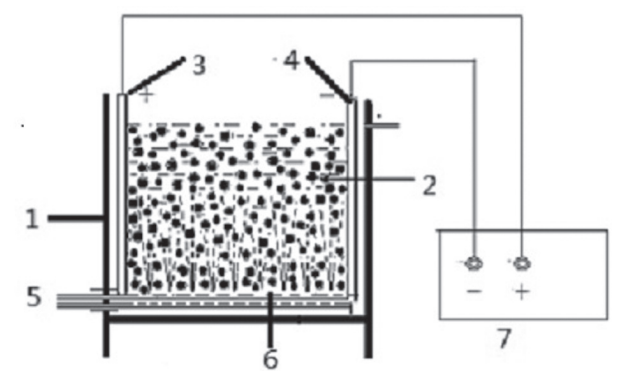

Figure 1. Schematic diagram of the 3D electrode reactor: (1) PVC reactor; (2) particle electrodes; (3) graphite anode; (4) stainless steel cathode; (5) compressed air; (6) air micropore plate; (7) power source.

\section{Analytical methods}

The concentration of phenol and hydroxyl radical were tested by UV-Vis spectrophotometer. The experimental 
results were assessed mainly by phenol removal efficiency $(\eta)$. The $\eta$ is calculated by the following equation:

$\eta(\%)=\frac{\mathrm{c}_{0}-\mathrm{c}}{\mathrm{c}_{0}} \times 100 \%$

where $\mathrm{c}_{0}$ and $\mathrm{c}$ denote the phenol concentration at initial time and given time, respectively.

\section{Results and Discussion}

\section{Characterization of metal oxides-doped CA}

Figure 2 shows the X-ray spectra of metal oxides-doped CA. The diffraction peaks centered at around $23^{\circ}$ are corresponding to (002) graphite diffraction. The characteristic diffraction peaks of metal oxides (such as $\mathrm{CuO}, \mathrm{ZnO}$ and $\mathrm{MnO}$ ) could be obviously observed from the Figure 2, and their strong and narrow diffraction peaks showed that these metal oxides were crystallized well. The characteristic diffraction peaks of NiO-doped CA could also be observed, but its relatively weak peaks indicated weak crystallinity of NiO. However, the X-ray spectra of $\mathrm{MnO}_{2}$-doped CA shows a very weak and broad peaks at around 36 and $65^{\circ}$, indicating the amorphous nature of $\mathrm{MnO}_{2}$. According to the Scherrer's equation, the mean sizes of all metal oxide crystallite samples (except $\mathrm{MnO}_{2}$ ) were centered between 13.99 to $26.06 \mathrm{~nm}$, the calculation results were listed in Table 1.

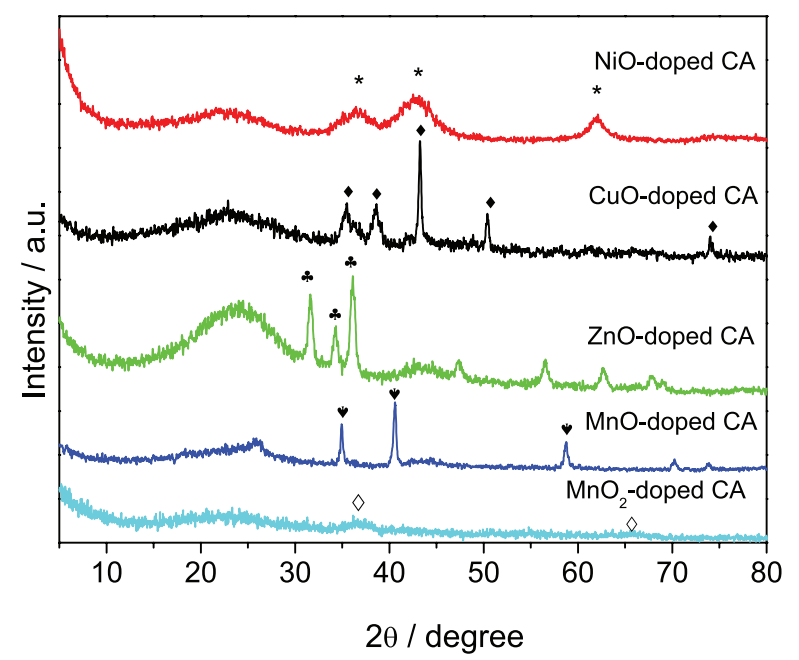

Figure 2. XRD patterns of metal oxides-doped CA.

Table 1. Mean size of metal oxides calculated by Scherrer's equation

\begin{tabular}{lccccc}
\hline Metal oxide & $\mathrm{NiO}$ & $\mathrm{ZnO}$ & $\mathrm{MnO}$ & $\mathrm{MnO}_{2}$ & $\mathrm{CuO}$ \\
\hline Mean size $/ \mathrm{nm}$ & 13.99 & 19.26 & 26.06 & - & 14.06 \\
\hline
\end{tabular}
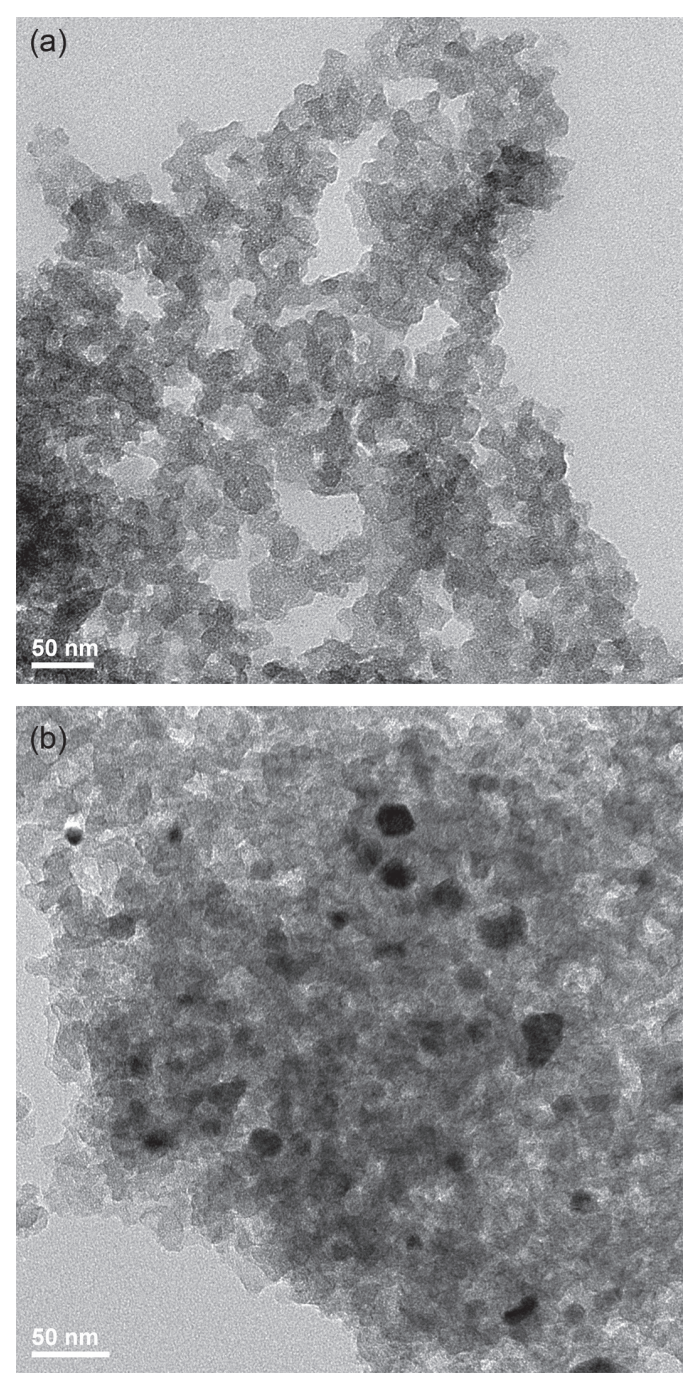

Figure 3. TEM images of (a) CA and (b) ZnO-CA.

In order to further investigate the influence of the metal oxides on the morphology of the CA, the TEM images of pristine $\mathrm{CA}$ and $\mathrm{ZnO}$-doped $\mathrm{CA}$ specimens are shown in Figure 3. It is observed that the CA nanoparticles with the size of about $30 \mathrm{~nm}$ aggregate to form the interconnected $3 \mathrm{D}$ network. After doping by $\mathrm{ZnO}$, the black nanoparticles in the size of about $15-30 \mathrm{~nm}$ could be noticed. It is demonstrated that the $\mathrm{ZnO}$ nanoparticles have been successfully incorporated into the inner part of the CA networks.

\section{Evaluation and analysis of catalytic activity}

The metal oxides $\mathrm{MnO}, \mathrm{CuO}, \mathrm{ZnO}, \mathrm{MnO}_{2}$ and $\mathrm{NiO}$ are used as catalysts for the oxidation of phenol in aqueous solutions, their electrocatalytic oxidation were performed in the 3D electrode reactor using metal oxides-doped CA. The pristine CA particle electrodes were also measured for contrast. 
As shown in Figure 4, the phenol removal efficiency decreased in different degree with an increase of number of runs, and the metal oxides-doped CA showed of a higher phenol removal efficiency than that of pristine CA. Moreover, the metal oxides-doped CA exhibited a higher stability than pristine CA after 50 runs. We can come to the conclusion that the presence of metal oxides within the mesopores of CA significantly enhanced the phenol removal efficiency, indicating that the metal oxides are beneficial to the phenol degradation due to the excellent electrocatalytic oxidation properties in the 3D electrode reactor. The phenol removal efficiency is strongly dependent on the type of metal oxides, and the $\mathrm{CuO}$ and $\mathrm{ZnO}$ showed the most efficient catalytic properties among all the metal oxides. After 50 batch runs, 93 and $81 \%$ of phenol was removed by the reactor with $\mathrm{CuO}$-doped $\mathrm{CA}$ and $\mathrm{ZnO}$-doped $\mathrm{CA}$ particle electrodes, respectively. Especially, $\mathrm{CuO}$-doped $\mathrm{CA}$ was the most active specimen, about $93 \%$ phenol could be removed after 50 runs as compared with the $100 \%$ removal for the tenth $\left(10^{\text {th }}\right)$ run, illustrating that the specimens remained active even after 50 runs. The result is consistent with the literature that the copper oxides exhibited high activity for the catalytic oxidation of organic water pollutants. ${ }^{11,12}$

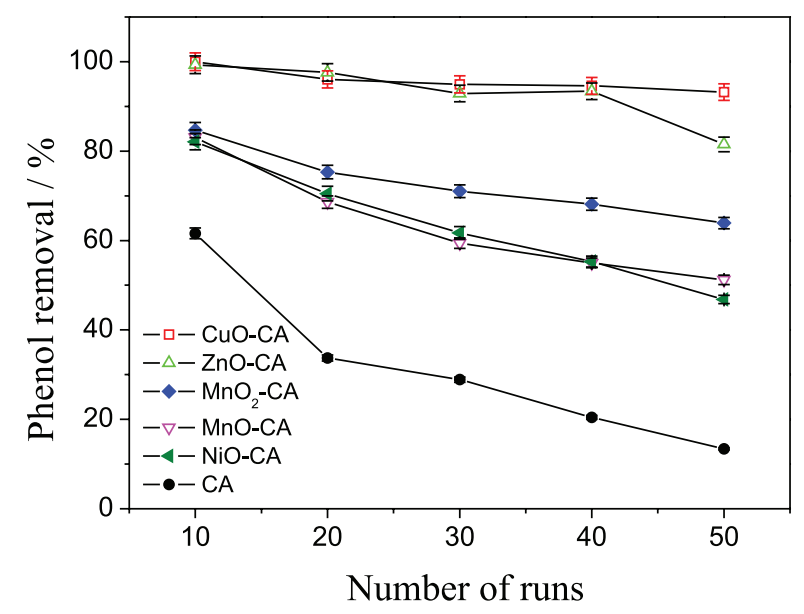

Figure 4. Phenol removal efficiency versus number of runs on metal oxides-doped CA using 3D electrodes reactor.

As also shown in Figure 4, during the first 10 runs, the $\mathrm{MnO}_{2}$-doped $\mathrm{CA}$ and $\mathrm{MnO}$-doped CA showed similar behavior towards the phenol removal efficiency. However, only 64 and $51 \%$ phenol was removed by the $\mathrm{MnO}_{2}$-doped $\mathrm{CA}$ and $\mathrm{MnO}$-doped CA particle electrodes after 50 runs, respectively. It is revealed that the $3 \mathrm{D}$ electrode reactor with $\mathrm{MnO}_{2}$-doped $\mathrm{CA}$ electrodes is more efficient than the reactor with $\mathrm{MnO}$-doped $\mathrm{CA}$ electrodes. Moreover, the phenol removal efficiency on NiO-doped CA showed a rapid decrease from 82 to $47 \%$ after 50 runs. Thus, the
NiO-doped CA is believed to be less efficient to degrade phenol than the other four metal oxide catalysts.

The semiconductors could be divided into n-type and p-type categories. The $\mathrm{CuO}, \mathrm{ZnO}, \mathrm{MnO}_{2}$ metal oxides are attributed to the n-type semiconductor while the $\mathrm{MnO}$ and $\mathrm{NiO}$ oxides are ascribed to p-type semiconductor. ${ }^{13}$ Based on the above results, the catalytic activity of $\mathrm{CuO}, \mathrm{ZnO}$ and $\mathrm{MnO}_{2}$ was higher than the other metal oxides including $\mathrm{MnO}$ and $\mathrm{NiO}$. It is suggested that their phenol removal efficiency should be related with the types of metal oxides, and the n-type metal oxides are believed to show higher catalytic activity towards the oxidation of phenol.

It is well known that the electrochemical process for phenolic compounds removal is a combination of surface adsorption, catalytic oxidation and desorption processes. It can be based on the transformation of oxygen into $\cdot \mathrm{OH}$ radicals, and $\bullet \mathrm{OH}$ radicals firstly form in the anode because of discharging of $\mathrm{H}_{2} \mathrm{O}$ on the anode surface, which tend to attack an aromatic ring to form a dihydric phenol quinone, or carbonyl compounds or carboxylic acids to produce the final product of $\mathrm{CO}_{2} \cdot{ }^{14} \mathrm{In}$ order to demonstrate the final products of electrochemical process for phenolic compounds removal on metal oxides doped CA, we explored phenol removal efficiency and chemical oxygen demand (COD) removal efficiency on metal oxides doped CA, and the corresponding results are shown in Table 2. The phenol removal efficiency and COD removal efficiency on NiO-doped $\mathrm{CA}$ and $\mathrm{ZnO}$-doped $\mathrm{CA}$ for 50 runs are both similar to each other, indicating a complete conversion of phenol under established conditions. This is because if the phenol removal efficiency is higher than the corresponding COD removal efficiency, it means that some phenol transformed to its intermediates or the degradation is complete. The evidence that the phenol removal efficiency and COD removal efficiency on NiO-doped CA and ZnO-doped CA keep consistent relationship reveals that the reaction products are mainly composed of $\mathrm{CO}_{2}$, which was also proved from Figure 5. As shown in Figure 5, it is noticed that the absorption peaks at 210 and $269 \mathrm{~nm}$ contributing to phenol gradually decrease and eventually disappear as the treating time increases. However, no other absorption peaks could be observed from the UV-Vis spectra, indicating absence of aromatic intermediates.

The electrochemical oxidation performance in electrochemical process is closely related to the efficient -OH radical generation. ${ }^{15}$ In order to further demonstrate that phenol was degraded mainly by $\bullet \mathrm{OH}$ radicals in the presence of metal oxides and study the relationship between the electrocatalytic oxidation activity of metal oxides and the $\bullet \mathrm{OH}$ radical generation quantity, the relative quantity or concentration of $\bullet \mathrm{OH}$ radical was measured by 
Table 2. Phenol removal efficiency and COD removal efficiency on NiO-doped CA and ZnO-doped CA for 50 runs

\begin{tabular}{llccccc}
\hline Run & & 10 & 20 & 30 & 40 & 50 \\
\hline \multirow{2}{*}{ NiO-doped CA } & Phenol removal efficiency / \% & 93.0 & 83.0 & 71.0 & 60.9 & 46.1 \\
& COD removal efficiency / \% & 91.9 & 82.1 & 70.5 & 61.7 & 46.8 \\
\hline \multirow{2}{*}{ ZnO-doped CA } & Phenol removal efficiency / \% & 98.3 & 97.6 & 92.9 & 92.3 & 81.5 \\
& COD removal efficiency / \% & 97.1 & 95.6 & 91.9 & 91.4 & 83.3 \\
\hline
\end{tabular}

CA: carbon aerogel; COD: chemical oxygen demand.

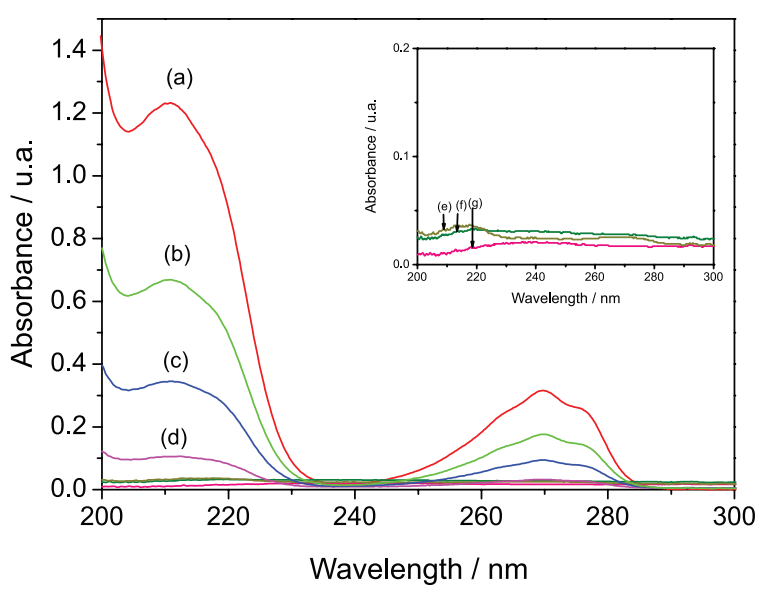

Figure 5. UV-Vis spectra of phenol during oxidation on the $\mathrm{ZnO}$-doped CA electrodes after different number of runs: (a) initial phenol solution; (b) $50^{\text {th }} ;$ (c) $40^{\text {th }}$; (d) $30^{\text {th }} ;$ (e) $20^{\text {th }}$; (f) $10^{\text {th }}$; (g) $5^{\text {th }}$ run.

UV-Vis spectrophotometry, and the quantitative analysis of $\bullet \mathrm{OH}$ radicals can be done through the colorimetric determination of 2,3-dihydroxybenzoate when salicylic acid instead of phenol was added to hydroxyl radical system and hydroxyl radicals are easy to attack salicylic acid to produce 2,3-dihydroxybenzoate. ${ }^{16,17}$ So we can understand that the absorbance of 2,3-dihydroxybenzoate is linearly related to the relative quantity or concentration of $\bullet \mathrm{OH}$ radicals, and the relative quantity or concentration of $\bullet \mathrm{OH}$ radicals can be measured. Following the test steps in the literature ${ }^{16,17}$ a certain amount of salicylic acid solution instead of phenol was added into the target reaction system. After electrolyzing for a certain time, then sampling, filtering and carrying out a series of sample handling steps, the absorbance of the target reaction system was measured at $510 \mathrm{~nm}$. We explored three target reaction systems for $\mathrm{MnO}_{2}$-doped $\mathrm{CA}$ and $\mathrm{ZnO}$-doped $\mathrm{CA}$ and the pristine $\mathrm{CA}$ using $3 \mathrm{D}$ electrodes reactor, and the absorbance of $\bullet \mathrm{OH}$ radicals in $3 \mathrm{D}$ electrodes versus time is shown in Figure 6. We can observe from Figure 6 that the absorbance of $\bullet \mathrm{OH}$ radicals in $\mathrm{MnO}_{2}$-doped $\mathrm{CA}$ and $\mathrm{ZnO}$-doped $\mathrm{CA}$ are higher than the one in the pristine $\mathrm{CA}$ and the absorbance of $\bullet \mathrm{OH}$ radicals in $\mathrm{MnO}_{2}$-doped CA was the highest. Moreover, absorbance of $\bullet \mathrm{OH}$ radicals was kept almost constant for $1 \mathrm{~h}$. This is because the concentration of $\bullet \mathrm{OH}$ radicals was very low $\left(<10^{-8} \mathrm{~mol} \mathrm{~L}^{-1}\right)$ due to very short lifetime $\left(10^{-4} \mathrm{~s}\right)$ of $\bullet \mathrm{OH}$ radicals when the reaction time was very short. By increasing the reaction time, sufficient $\bullet \mathrm{OH}$ radicals concentration can be generated, which react with salicylic acid to produce sufficient 2,3-dihydroxybenzoate, resulting in an almost constant absorbance. So, based on the above results from Figures 4 and 6, we think that the type of semiconductors is related to the catalyst activity of $\bullet \mathrm{OH}$ radicals production. The presence of metal oxides accelerated $\bullet \mathrm{OH}$ radicals generation. The - $\mathrm{OH}$ radicals quantity depends on the type of metal oxide. The n-type metal oxides are believed to show higher catalytic activity towards the oxidation of phenol, due to the efficient - $\mathrm{OH}$ radicals generation. n-Type semiconductors are more active than p-type semiconductors.

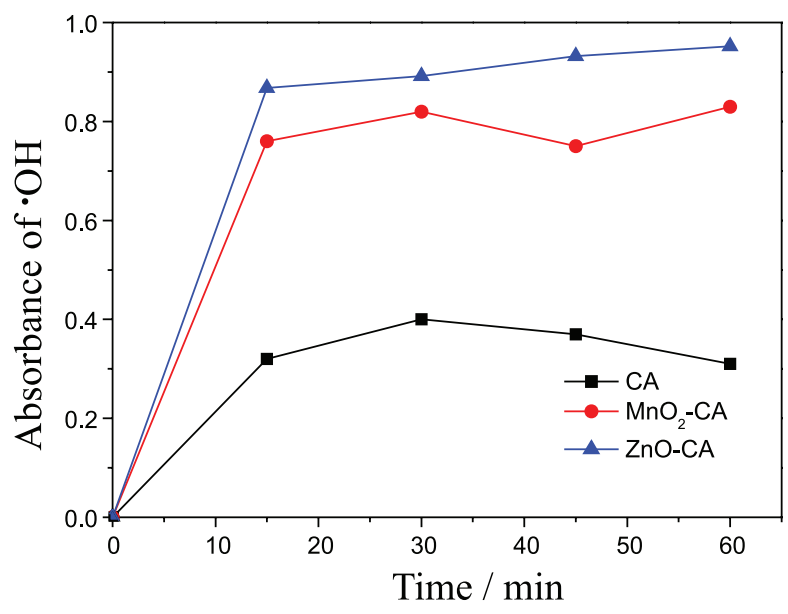

Figure 6. Absorption of $\bullet \mathrm{OH}$ radicals in $3 \mathrm{D}$ electrodes versus time.

\section{Conclusions}

Metal oxides-doped CA have been prepared and used as particle electrode materials, and the metal oxide particles were dispersed separately throughout the carbon matrix, the particle size was centering between $15-30 \mathrm{~nm}$. The catalytic activity was conducted for the aqueous phase phenol oxidation in a $3 \mathrm{D}$ electrode reactor. The metal oxides doped on CA during the phenol degradation were able to catalyze oxygen to generate $\cdot \mathrm{OH}$ radicals. The catalytic activity depended on the semiconductor type of metal oxide. 
The n-type semiconductors catalyzed oxygen to generate $\bullet \mathrm{OH}$ radicals more actively than that of p-type semiconductors. The catalytic activity of metal oxides was in the order $\mathrm{CuO}>\mathrm{ZnO}>\mathrm{MnO}_{2}>\mathrm{MnO}$ and $\mathrm{NiO}$. The final products of phenol degradation removal and generation of - $\mathrm{OH}$ radical by metal oxides doped $\mathrm{CA}$ was demonstrated.

\section{Acknowledgments}

This research was supported by the Project of JAAS Youth Foundation (2014CQN006) and the Scientific and Technology Support Plan Foundation of Jiangxi Province (20151BBF60033, 2016ACF60023).

\section{References}

1. Polcaro, A. M.; Palmas, S.; Ind. Eng. Chem. Res. 1997, 36, 1791.

2. Sogaard, E. G.; Chemistry of Advanced Environmental Purification Processes of Water, $1^{\text {st }}$ ed.; Elsevier: Amsterdam, UK, 2014, ch. 3.

3. Ji, F.; Li, C.; Deng, L.; Chem. Eng. J. 2011, 178, 239.

4. Induja, S.; Raghavan, P. S.; Catal. Commun. 2013, 33, 7.
5. Christoskova, S. T.; Stoyanova, M.; Water Res. 2001, 35, 2073.

6. Jacobs, J. P.; Maltha, A.; Reintjes, J. G.; Drimal, J.; Ponec, V.; Brongersma, H. H.; J. Catal. 1994, 147, 294.

7. Zhang, C.; Jiang, Y.; Li, Y.; Chem. Eng. J. 2013, 228, 455.

8. Xiao, M.; Zhang, Y.; Chemosphere 2016, 152, 17.

9. Wu, X.; Yang, X.; Wu, D.; Fu, R.; Chem. Eng. J. 2008, 138, 47.

10. Lv, G.; Wu, D.; Fu, R.; J. Hazard. Mater. 2009, 165, 961.

11. Pintar, A.; Levec, J.; J. Catal. 1992, 135, 345.

12. Akyurtlu, J. F.; Akyurtlu, A.; Kovenklioglu, S.; Catal. Today 1998, 40, 343.

13. Netzer, F. P.; Fortunelli, A.; Oxide Materials at the TwoDimensional Limit, Part 9, $1^{\text {st }}$ ed.; Springer International Publishing: Switzerland, 2016.

14. Alejandre, A.; Medina, F.; Salagre, P.; Fabregat, A.; Sueiras, J. E.; Appl. Catal., B 1998, 18, 307.

15. Li, X.; Cui, Y.; Feng, Y.; Xie, Z.; Gu, J.; Water Res. 2005, 39 , 1972.

16. Halliwell, B.; FEBS Lett. 1978, 92, 321.

17. Jia, Z.; Wu, J.; Tang, M.; Prog. Biochem. Biophys. 1996, 23, 184.

Submitted: August 16, 2017

Published online: October 13, 2017 